Francis Babayemi, Antonija Lujanac, Martina Paone, Sanja Skreblin Ezratech Limited, Osnovna skola Dobrise Cesarica, BOS school, Osnovna skola Dobrise Cesarica fb@ezratech.co.uk, antonija.lujanac@skole.hr, martinapaone.bos@gmail.com, sanja.skreblin@skole.hr

\title{
The Importance of School Libraries in Open Schooling, Sustainable Development, and Outdoor Learning
}

\begin{abstract}
This paper reports the preliminary results of a 2020/2021 research project about open schooling, Sustainable Development Goals (SDGs), and outdoor learning in Europe and the role of school libraries in implementation and development of Open Education Resources (OER). School librarians support learners who have been unable to access schooling, but also the learners who are in school, but are not learning effectively. School librarians as Information and Communication Technology (ICT) and educational experts have all important skills to support teachers and students in development and using an OER. Innovative distance learning needs to be established for monitoring, evaluation, quality assurance, and continuous improvement. The SDGs could be achieved only if local communities ensure open access to education.
\end{abstract}

Keywords: sustainable development; outdoor learning; open education resources

\section{Introduction}

When you start to make plans for the next months or years, do you feel ready for "the radical changes?" Is "the radical change" something destructive or a great renewal? How radical are you ready to be in changing your everyday life? The pandemic marked the end of the dark Middle Ages and the start of a great cultural renewal. Actually, the Renaissance started when scholars of the Byzantine Empire migrated to Europe in the 15th century, bringing their libraries with them. Can you imagine the impact of the new way of thinking they discovered in ancient books? Thanks to radical changes of mindset in the 15 th century we can enjoy the renaissance of art, science, music, architecture, medicine, economy, etc.

Every human has the right to use this heritage. The only radical change we have to put in our plans for the next months or years is to be ready for open schooling, sustainable development, and outdoor learning. Let us tell you the story about the project Open Communities for Sustainable Development (OUTSIDE) and the role of libraries in development and 
implementation of the project. The OUTSIDE renaissance started in Italy in cooperation with educators from Belgium, Lithuania, United Kingdom (UK), and Croatia during lockdown.

During the pandemic, educators from Belgium, Lithuania, Italy, Croatia and the UK started the new Erasmus ${ }^{+}$project called Open Communities for Sustainable Development (OUTSIDE). The goals of the project are the creation of an innovative framework, Open Education Resources (OER), training for teachers, research, manuals, and good practice exchange in open schooling and outdoor learning. The role of school librarians was important in every phase of the project because "school librarianship is a highly collaborative and people-focused profession” (Reed \& Tharp, 2019).

School libraries have an existing role of supporting both educators and students, curating content for educational needs, and promoting transversal skills (Welz, 2017). Therefore, school libraries are considered uniquely well placed in providing leadership in OER creation, collation, and distribution. This is evidenced in the valuable contribution of school libraries to the implementation and outcomes of the OUTSIDE research project thus far. The libraries have been able to successfully collaborate within the school and the local community to provide comprehensive insight into the educational structures and culture of the region, identifying specific needs of relevant stakeholders. The high quality of research will help to ensure the final outputs of the OUTSIDE project have value, relevance, and practicality.

The project OUTSIDE aims to encourage the creation of Open Communities of Learning (OCL) aimed at promoting entrepreneurial spirit and awareness of environmental and sustainability issues among young people, establishing contacts between the public and private sectors, and involving schools, companies, and interested bodies. The project is based on the necessity of meeting two fundamental needs:

1. Promoting the acquisition of key and innovative competences among students.

2. Promoting environmental and sustainable development education through the integration of the 17 Sustainable Development Goals (SDGs) from the United Nationsinto the relevant education systems.

\section{Statement of the Research Problem}

The aims of the research were to investigate open schooling, outdoor learning, environmental education and sustainable entrepreneurship in Italy, Croatia, Lithuania, and Belgium. The research has been divided into two phases: desk research and field research. The second phase of the research presents the results from the field research where partners involved local stakeholders and students to investigate the current offerings in sustainable entrepreneurship and the training needs. The compared analysis of both desk research and field 
research is presented in this paper and it constitutes the basis for the design of training modules and a training toolkit for teachers. One of the project partners is the Croatian School Library Association and we were interested in implementation of the research results in the local community through the program of the school library.

\section{Literature review}

There is a huge need to establish and support multidisciplinary teams for open access contents, methodology, technical, and editorial input to ensure development of appropriate OER. Teachers need training and support to motivate, mediate, and assess learning at a distance. The school librarians from Croatia, the facilitators from the UK, the teachers from Lithuania and Italy, and the educators from non-governmental organizations (NGOs) are responding to these needs by developing innovative, multilingual OER in cooperation with their local communities. The implementation of the OUTSIDE project activities in Croatia were through the school library program. Developing this program "requires the teacher librarian to have a good relationship with the school community" (McPherson, 2020).

There are different views on open education, open schooling and Open Educational Resources (OERs). Open education has been around for over 50 years. In countries which already had established open schools (Botswana, India, Namibia, Canada, New Zealand) it refers to the openness of the system to everybody who missed out on schooling in childhood or because of physical distance from the school. Open schooling in the European context is "an open, curious, welcoming, democratic environment which supports the development of innovative and creative projects and educational activities" (Sotirio et al., 2020). The United Nations Educational, Scientific and Cultural Organization defined OERs as "teaching, learning, and research materials in any medium, digital or otherwise, that reside in the public domain or have been released under an open license that permits no-cost access, use, adaptation, and redistribution by others with no or limited restrictions. Open licensing is built within the existing framework of intellectual property rights as defined by relevant international conventions and respects the authorship of the work" (UNESCO, 2012).

Charles Wedemeyer articulated the concept of open education as a "mix of multiple features, of which all may not be present in one system: opening education to more people, open admissions, using multiple channels of communication, open curriculum, open access to learning from anywhere, encouraging open participation, open accreditation, and open sharing" (Wedermayer, 1973). In recent times, as David Kember (2007) puts it, open education/learning has been more about "removing barriers to participation" in learning. So, open education is about open entry, study anywhere, anytime, and flexibility to choose courses. Any education system 
can demonstrate the attributes of openness as identified by Wedemeyer, and the learning resource is just one of these.

The modern concept of open education we could deliberate in terms of Fairness, Flexibility and Freedom (Mishra, 2017). Fairness relates to equity and social justice. The cost of education is a barrier to increasing access to education for all. So, it is appropriate for OER practitioners to urge for open licensing of educational resources that are developed with public funds. This has now become part of the OER Recommendation approved by UNESCO General Conference in November 2019. Flexibility refers to the range of options available to learn. Flexibility to choose from a range of massive open online courses (MOOC) to graduate has become a norm in many countries. A flexible learning system allows a range of affordances to learners helping them learn in their own space and at their own pace. Freedom of open education is from the perspective of OER, where the learning resources used in teaching and learning are not only available at zero cost, but are also available in accessible format with open license to reuse, revise, remix, and redistribute.

Creating teaching and learning resources with open license and making them available requires not only a shift in the proprietary mindset but also an attitude of giving, and not greed to profit out of public good. Changing mindsets is a slow process, thus government intervention to proclaim policy/law through legislative or executive process to make all publicly funded resources with open license available is key to further progress. Availability of teaching and learning materials with the freedom to repurpose and to contextualize them provides new avenues for teachers and learners to rethink their pedagogical practices and improve student learning (Mishra, 2017). In developing the innovative and resilient education systems, some stakeholders from Europe have realized the need to learn more from the diversity of experiences which have disrupted learning. OERss offer high-quality education to every student and it is one of the most popular resources in promoting sustainable development, open schooling, digital learning, and open-license knowledge sharing in Europe.

\section{Methodology and research findings}

The aim of the initial phase of research undertaken by the OUTSIDE consortium was to provide a comprehensive overview of the current educational offering in each partner country with regards to open schooling, outdoor learning and sustainable entrepreneurship education. In particular, the consortium sought to identify existing competencies in these topics, of both students and teachers, and to assess the gaps and needs in schools and the local community. The research which was conducted in January and February 2021, was split into two parts: a desk research task and a field research task, carried out by each partner country, at the national level. 
In the desk research task, the main objectives were, firstly, to identify the existing project-based learning, open schooling, and sustainable development education in each country and the methodologies, strategies, and tools already used to promote such knowledge. The second objective was to identify the key innovative competencies gained by students in these topics. The last two objectives were to identify ways of improving the entrepreneurial, digital, and environmental knowledge of students with respect to meeting sustainable challenges and to improve promotion of environmental and sustainable development education in the local education system. In effect, the desk research aimed to identify how well, if at all, open schooling and sustainable development education align with the "Quality of Education" targets set in the 2030 Agenda for Sustainable Development (United Nations, 2020), within each piloting country.

The approach used to achieve this was to provide a questionnaire template for each partner to complete, that would create a case-study of the education systems and culture for each country. The questionnaire consisted of semi-open questions mapped to the European Entrepreneurship Competence Framework (EntreComp) and partners were encouraged to provide specific details and examples of existing education offerings and initiatives.

In the field research task, each piloting country organised two focus groups of 5-12 participants, one with students from the partner schools, and the other with local community representatives and stakeholders, such as environmental associations, green entrepreneurs, and education experts. The objectives of these focus groups was to identify training needs of students and the local community in sustainable development education and green entrepreneurship and to identify preferences of training opportunities in these topics. Additionally, the focus groups aimed to identify any possible local synergies and to map the specific needs of the local region where the pilot framework will be implemented.

A single final report template, also mapped to the EntreComp Framework, was completed using the responses of the focus groups from each partner country. Guidance scripts were developed and provided to facilitate each focus group, providing an introduction of the project, expectations of participant behaviour and engagement, as well as suggested questions to help maximize the output of the sessions.

Each of the research tasks were conducted using a single template, developed and agreed upon by the OUTSIDE consortium, which facilitated data handling, ensured consistency in the data collection and analysis, and enabled comparability of responses.

\section{Findings in Belgium}


Education in Belgium is regulated and, for the most part, financed by one of the three communities: Flemish, French and German-speaking. Despite the sensible differences among communities, the research found similarities in the educational approaches towards environmental education, outdoor learning, and entrepreneurship. The Agenda 21 (United Nations Conference on Environment and Development, 1992) for schools proposed a series of instruments and helped to include sustainable development in their institutional project. For instance, a cooperation agreement between Walloon Region and the Federation Wallonie Bruxelles has been signed to promote environmental education in schools and to establish a series of structures, associations, and goals to pursue the SDGs in the school curricula.

Outdoor learning is gaining popularity in Belgium, with the growth of Forest Schools, outdoor education networks (the most important of which is "Tous Dehors"), and the weekly participation of some public schools in outdoor classes. There is a vast availability of resources for teachers (more of which are teaching modules than training toolkits for students) about outdoor learning and environmental education, whereas there is a scarcity of training in sustainable entrepreneurship. The majority of these trainings are provided by NGOs and networks of NGOs, directly or indirectly state funded.

Despite the presence of a wide array of training, and the multiplications of outdoor educational activities, the phenomena is still quite marginal, and the acquisition of knowledge and the start of outdoor activities is however left to the interest of the single teacher, and not really embedded organically in the school system.

The absence of a structural facilitation for teachers produces the fact that outdoor classes, as well as classes on environmental education and green business, are a marginal, sporadic, extra-curricula event and not embedded in the curricula. If only a minority of teachers are inclined to spend time in extra-school training on outdoor learning, there is an even greater lack of interest and knowledge about sustainable entrepreneurship, causing the entrepreneurial activity rate of young Belgians to be the lowest in the European Union.

According to the research results, "open schooling", remains still an unknown subject, although in practice little actions are undertaken to link schools with external organizations. Further barriers to the integration of the OUTSIDE's topic into the school education in Belgium is the obligation to respect a rigid school curriculum, the lack of interdisciplinary view, the lack of support for teachers that are interested in pursuing innovative teaching (outdoor, environmental education etc.), and legal and logistic constraints of the schools (problem in regularly bringing children outside, lack of staff, etc.).

\section{Findings in Croatia}


The Croatian educational reform called School for Life met a great deal of change in the national educational system, as it included sustainability as an important topic to teach, as well as civic education. At the same time, the interest in schools and teachers for outdoor learning and connection with local communities seems to be gaining momentum. Despite many activities carried out outdoors in connection with the community, most of these tend to be sporadic, without a long-term impact, and not really embedded in the school curricula. To obtain data for this research, twenty-nine teachers in the Osnovna skola Dobrise Cesarica have replied to a questionnaire. They expressed that $58 \%$ of the teachers organize such activities two or more times per year, $24 \%$ organize it only once per year, and $16 \%$ never organize such activities. In general, great importance in the drive for outdoor learning activities and training relies on external organization and European projects. Still, some barriers to undertake outdoor activities and links with communities are due to structural problems (teachers are not enough supported by the school), logistics (lack of time, lack of adequate preparation), and cultural (feeling of lack of security from parents), whereas creative and entrepreneurial workshops exclude less talented students and disabled students.

The concept of open school is a new one in Croatia, but there is a growing interest. The novelty is mostly on the term itself and its conceptualization, as cooperation among schools and local realities are in place, but not in a structured way, and not referred to as the term "open schooling." Most importantly, entrepreneurship seems to be still an underdeveloped subject, mainly due to teachers' lack of competencies in this subject. There is a need to organize teachers' training about entrepreneurial competencies with a cross-curricular focus. Both stakeholders and students consider extremely salient the development of open schooling and outdoor learning in the view of increasing green business actions. Students particularly showed great interest in outdoor learning and sustainable development, showing willingness to learn more organizational skills, negotiation, ethical business, creativity, critical thinking, and emotional self-control.

\section{Findings in Italy}

The Plan for Education to Sustainability from the Italian Ministry for Education and Research has outlined actions to be undertaken in the field of education, with the aim of meeting the goal n. 4 of the Agenda 2030 and contributing to the transition to a more sustainable society with the support of knowledge and education. It is also remarkable to notice that since 2019, teaching "civic education" has become compulsory (many topics related to sustainability literacy are included). In addition to the pedagogic initiatives, several infrastructural investments are to 
be made to promote the energetic efficiency of schools and to implement extracurricular activities on several topics.

At the school level, the research showed that there is a superficial understanding of the project's topics (entrepreneurship, open schooling, outdoor education, sustainable development): some topics are often mixed up, and, in particular, there is a scarce understanding of EntreComp. There are, however, several resources on the OUTSIDE's topics (coming from schools or training providers). There are several synergies on outdoor learning, existence of initiatives aimed at opening up the schools to the community, and innovative processes in the educational system connected to the development of entrepreneurship literacy.

The presence of a policy framework does not allow, however, a systematic application at the curricular level, showing a mismatch between knowledge and practical application.

There is indeed a lack of systematic approach in teaching the project's topics, which lead to one-off events/initiatives with short term impact. There are indeed interesting initiatives, most of them are, however, addressed to primary schools, but not embedded in the curriculum. Regarding entrepreneurial literacy, although in 2018 Italy has adopted a dedicated strategy to fully integrate entrepreneurship education into school systems, the entrepreneurship education is still far from being systematically implemented by the Italian schools. While an increasing number of entrepreneurship education activities exist today compared to a decade ago, scalability and penetration remain key challenges.

These shortfalls are mainly linked to the lack of integrated approach (scarce systemic integration of innovative teaching/learning experiences in the curriculum), to the lack of an interdisciplinary approach, and to the little confidence and support in experimenting with innovative approaches (e.g. issues of safety for activities taking place outdoors). Moreover there is a lack of knowledge, in particular on the topic of entrepreneurial competences.

The analysis of the students' view of the connection between Sustainability and Entrepreneurship reflects what was observed in the desk research: they engaged in occasional outdoor activities, but not in a systemic long-term engagement. Despite this, students showed quite a large interest in the OUTSIDE project, both for its European dimension and for the topics it tackles. Students linked environmental sustainability with the well-being of the future generations, showing empathy and care for the local community (mainly related to the topic of pollution, waste management, resources, waste, etc.). Several students said that they have taken part in outdoor activities related to environmental education. Students showed a lack of vision on imagining how to build sustainable systems and projects and a willingness to understand more in depth what environmental sustainability entails, both theoretically and practically. The local challenges identified were the following: lack of green areas, environmental pollution, lack of 
civic awareness, and waste production. Students also highlighted possible green business initiatives to tackle these problems.

\section{Findings in Lithuania}

The Lithuanian education system is decentralized, leaving educational institutions and teachers a free interpretation of the General Programs and Education Standards. This therefore creates a diversity in reception of concepts as outdoor learning, open schooling, and entrepreneurship among schools. Overall, despite the great importance of nature in the country, and the great prominence of green spaces, outdoor learning is not very popular, due to the fact that it is a very new concept in Lithuania, as the first outdoor learning kindergarten was established in 2014. Many schools only limit themselves to organizing sporadic outdoor activities or programs that last just one or few days over the course of the year. However, there is a new trend in establishing "outdoor classrooms" and funding for forest schools is growing. Outdoor kindergartens are being established in major cities of Lithuania (Kaunas, Vilnius, Klaipeda). There is one primary field school in Vilnius, which is based on the experience of Scandinavian field pedagogy, experience, and the principles of free play.

The major limits to this might be found in the lack of guidelines from the policymakers and the government side for school management teams to blend the outdoor learning with formal academic learnings. Lack of advertisement and promotion on outdoor learning through media also lacks in the country. There is no official training offered for teachers on these topics, therefore teachers get trained mainly via Erasmus Plus and Nord Plus programs. To be noticed is also the lack of assistance from health experts or environmental experts that could lobby for making outdoor learning a committed part of the general academic or extracurricular learnings.

The concept of open schooling and sustainable entrepreneurship appear to be new and underdeveloped ones. There are different individual initiatives but there is no one national strategy that would encourage sustainable entrepreneurship education in Lithuania's school system.

Concerning entrepreneurship, the importance of the subject is well emphasized in strategic documents of the Republic of Lithuania. However, a separate subject is not consistently available in Lithuanian general education schools singled out, but only in specific studies. This is mainly due to the lack of knowledge of teachers. Teachers possess a great array of techniques and tools to develop creativity, social skills and critical thinking, but this is not put at the service of entrepreneurial literacy yet. Despite that, both national surveys and field research conducted in the framework of OUTSIDE project show that there is a great interest from students in learning 
more about environmental sustainability. Moreover, data for external surveys also shows that there is a great interest from young people in starting up sustainable businesses.

\section{The Analysis of Research Results}

The final analysis of the outcomes of these two research activities identified the following common trends. Firstly, that all four partner countries have undergone national educational reforms that include some increased emphasis on environmental, sustainable and entrepreneurial education, however in every case there is a lack of strategy or framework to embed these topics into schools' curricula. Three of the four countries enforced a compulsory civic education module, including some topics on sustainable literacy. However, entrepreneurial education was rarely observed as a significant component of the curriculum, with the EntreComp Framework largely unknown or not considered, and was even less likely to be linked to sustainability. The interdisciplinary aspects required for successful sustainable entrepreneurship education was also found to be lacking in most school curricula.

A second common trend identified was the growth in interest of outdoor learning, with an increasing number of forest schools and outdoor classrooms observed in each country. However, for the majority of schools, outdoor learning activities are sporadic events relying on the discretion of individual teachers, rather than embedded in the school system, hindering any potential long-term benefits.

Open schooling was mostly regarded as a novelty and unknown concept by the research participants from all partner countries. However there was some evidence of open schooling practices in place in Croatia and Italy, despite the terminology being unfamiliar.

All research participants, particularly students, expressed interest in the topics and goals encapsulated in the OUTSIDE project. Teachers and stakeholders, while expressing significant interest, noted several barriers to implementing innovative educational paradigms, such as a lack of knowledge and training, particularly in outdoor learning and entrepreneurial education. This is combined with the logistical barrier of finding time within the established curriculum, as well as finding appropriate resources, if available. Participants also cited legal and cultural concerns around taking children and young people out of the classroom.

Finally, in terms of existing educational resources, most were found to be provided by European programmes and NGOs, with very few sourced from government educational authorities or schools. All partner countries found that, in general, there are educational resources available to educators around outdoor learning and environmental education subjects. However, there is a shortage in terms of entrepreneurship, particularly sustainable entrepreneurship, and 
little inclusion of open schooling methods throughout. Additionally, where resources are available, they are not held in a recognized, accessible, centralised location.

Overall, these results show a need to meet the educational deficiencies around the OUTSIDE topics in a systematic and entrenched manner, and for a virtual platform to unite educational resources for easy distribution.

It is important to notice that in the four piloting countries we could identify several common trends:

- National education reforms have been put in place in the four countries, to include environmental education, sustainable education, and entrepreneurship, but not enough has been done yet to include these aspects in the school curricula.

- There is a general growth of outdoor learning: opening of forest schools, new programs on environmental education, and networks on outdoor learning are blossoming, but the creation of outdoor activities in schools remains a choice of the single teacher, and often as a one-off event.

- Entrepreneurial education is still missing as a real component of the school curricula and it is almost never linked with sustainability.

\section{Implications and conclusions}

Based on the result of both phases of the research, and on the study of the training offers and needs, OUTSIDE project team attempted to draft a preliminary syllabus for the training modules that will be all incorporated in the Teacher Toolkit. Suggested modules include:

1. Knowing nature to protect the world

2. Taking learning outdoors

3. Stakeholders' engagement

4. How to turn an environmental challenge into a business opportunity

5. Sustainable Development and Project management

6. Green business strategy

7. Green Business Plan

8. Boost your green ideas through ICT

The OUTSIDE Educational Resource Center will contain the authentic material created by the project partners during the experimentation of the OUTSIDE methodology, as well as material (policy papers, projects, best practices, research, studies, etc.) focused on innovation in education applied to environmental protection and sustainability through open schooling useful for teacher training. 
If we want open education to succeed, we need to rethink what we do and how we do it, collectively. We need to be more inclusive and focused on developing appropriate policies that allow copyright holders to decide how they want to share. Such policies need to be developed at both national and institutional levels to guide relevant stakeholders in optimizing the resources available through different types of licenses and include non-derivative licenses as Open Educational Resources (OER). We need to build and demonstrate models that would enable better understanding of the remixing challenge posed by different licensing conditions.

Teachers and students are the most important stakeholders in the OER ecosystem. It is important to encourage them on a regular basis in the use and creation of OER, including ways for remixing and integrating in teaching and learning. Sustainable development is one of the most important cross-curricular topics in modern education. School librarians as pedagogical and informational experts with a flexible program can be involved more in research, testing, and implementation of the innovative, global approaches into the regular school curriculum.

School libraries are known to be specialists in providing interdisciplinary knowledge and support for both teachers and students. Consequently, with their unique position in the education system and wealth of experience, school libraries are ideally placed to drive OER development. Furthermore, the contribution of school libraries to the research tasks and to the wider goals of the OUTSIDE project presented in this paper, is an exemplary demonstration of how libraries can play a fundamental role in the development of OER-based pedagogy and, thus, the innovation of education for the future.

\section{References}

Clephane, S. (2014). New Zealand school librarians: Technology leaders? School Libraries Worldwide, 20(2), 14-27.

European Commission. (2019, April 3). Employment, social affairs \& inclusion:

EntreComp: The European Entrepreneurship Competence

Framework. https://ec.europa.eu/social/main.jsp?catId=738\&langId=en\&pubId=8 201\&furtherPubs=yes

Kember, D. (2007). Reconsidering Open and Distance Learning in the Developing World: Meeting Students' Learning Needs (1st ed.). Routledge. https://doi.org/10.4324/9780203966549 
McPherson, M. (2020). The influence of teacher librarians' personal attributes and relationships with the school community in developing a school library program. School Libraries Worldwide, 26(1), 136-150.

Mishra, S. (2017). Open educational resources: Removing barriers from within. Distance Education, 38(3), 369-380. https://doi.org/10.1080/01587919.2017.1369350

Sotiriou, S., Cherouvis, S., Zygouritsas, N., Giannakopoulou, A., Milopoulos, G., Mauer, M., Stockert, A., Bogner, F., Verboon, F., \& de Kroon, S. (2017). Open schooling roadmap: A guide for school leaders and innovative teachers. Ellinogermaniki Agogi. https://portal.opendiscoveryspace.eu/sites/default/files/u34111/osos-all.pdf

Phillips, S. (2007). Exploring the potential of open schooling. Commonwealth Education Partnership. https://www.cedol.org/wp-content/uploads/2012/02/19-22-2007.pdf

Prospero, M. (2021). Open Communities for Sustainable Development (OUTSIDE). Scienetix: The community for science education in Europe.

Reed, K., \& Tharp, T. (2019). Application of the teacher citizenship behavior theory to the extra-role work of school librarians. School Libraries Worldwide, 26(1), 48-60.

United Nations (2015). Transforming our world: The 2030 agenda for sustainable development. Sustainable Development Knowledge Platform. https://sustainabledevelopment.un.org/content/documents/21252030\%2 0Agenda $\% 20$ for $\% 20$ Sustainable $\% 20$ Development $\% 20$ web.pdf

United Nations Conference on Environment and Development. (1992). Agenda 21, Rio Declaration, Forest Principles. New York: United Nations.

Wedemeyer, C. A. (1973). Characteristics of open learning systems. Report of NAEB Advisory Committee on Open Learning Systems to NAEB Conference (New Orleans, Louisiana, November 1973). ERIC. 
Welz, K. (2017) School librarians and open educational resources aid and implement common core instructional content in the classroom. Knowledge Quest, 45(4), 63-68. 